\title{
LAPURDUTH
}

Euskal ikerketen aldizkaria | Revue d'études basques |

Revista de estudios vascos | Basque studies review

$9 \mid 2004$

Numéro IX

\section{Ohar lexikografikoak E UrkizurenBertso zahar eta berri zenbaiten bilduma (1798)-z}

\section{Charles Videgain}

\section{OpenEdition \\ Journals}

Édition électronique

URL : http://journals.openedition.org/lapurdum/889

DOI : 10.4000/lapurdum.889

ISSN : 1965-0655

Éditeur

IKER

Édition imprimée

Date de publication : 1 novembre 2004

Pagination : $321-327$

ISBN : 2-68781-376-X

ISSN : $1273-3830$

Référence électronique

Charles Videgain, «Ohar lexikografikoak E UrkizurenBertso zahar eta berri zenbaiten bilduma (1798)-z », Lapurdum [Linean], 9 | 2004, Sarean emana----an 01 mars 2009, kontsultatu 23 avril 2019. URL : http:// journals.openedition.org/lapurdum/889; DOI : 10.4000/lapurdum.889 


\title{
Ohar lexikografikoak P. Urkizuren Bertso zahar eta berri zenbaiten bilduma (1798)-z
}

\author{
Xarles VIDEGAIN \\ UPPA \\ IKER 5478 CNRS
}

Biga bostetan erakutsi du Biblioteketan lo dauden dokumentu ezezagunen argitara emateko duen ganorea Patri Urkizuk eta 1987. urtean euskaldungoari eskeini zion Baionako Euskal Museoan zegoen esku-idatzi baten testua. Manuel de la Sota-ren fondoan aurkitu zuen erdarazko titulu hau ekartzen zuen bilduma : Recueil de quelques pièces de vers / anciens et nouvea ux (1798). Xehetasun gehiago nahi duenak joko du beraz argitaralpen hortara.

Duela urte zonbait, liburu hau euskarazko CAPES azterketako programan izanki, lexikoaren inguruan mugatuz pundu batzu ilunik gelditzen zirela ohartu baikinen, xehetasun berri zonbaiten ematera entseatuko gara artikulu honetan. Bere liburuan hiztegi bat eskaintzen zuen Urkizuk 191-216 orrialdeetan, eta hiru informazio ematen zuen sarrera bakoitzeko : lehenik euskarazko hitza (dokumentuko ortografiaren arabera, aldaketa guti zonbait salbu), gero frantsesezko erranahia, eta hirugarrenekorik gaztelerazko erranahia.

Gure lana ez da exhaustiboa bainan hiztegi hartan ageri diren arazo batzu aipatu nahi izan ditugu. Alde batetik, frantsesez diren huts tipografikoak altxatu ditugu, baita ere frantsesezko eta gaztelerazko baliokideen arteko kontresanak, bestetik, itxasoari buruzko eta modari buruzko hitzen erranahi berri batzu ematen ditugu (heien artean izen amankomun bilakatu izen berezi zonbait : greka, fontantxa, xantal), azkenik beste hitz batzu zuzendu nahi izan ditugu (erlaxa, papaio, khorrokan, purriña, ttinpla).

ANTAPARA, bief, canal de molino, 143. Egia da Orota riko Euskal Hiztegiak (hemendik aintzina $\mathrm{OEH}$ ) adiera hori ematen duela bainan 'dique' ere bai (zentzu figuratua izan ditekeela dio OEH-k). Duvoisinek eman adiera aipatzen du OEH-k : 'digue, môle, jetée' eta adiera horrekin glosa diteke antapara hitza. Bainan erreferentea edo adierazia mendia dela dio testuak eta ez uste izaiteko zen bezala, frantsesez 'tombolo' deitzen den lurrezko edo harrokazko adarra. Mendiak beraz, 'digue' baten zeregina egiten badu, 'protection', 'abri' hitzez ere glosa diteke antapara hitza, kontuan hartzen dugularik errannahi honetatik ez dagoela urrun gazt. a ntipa ra. 
APASTA, boëtte, raba, 185. 'Appât' ere eman zitekeen, hots hiperonimoa. Gazt. 'raba'-ri fr. 'rogue' dagokio, apasta berezia baita, gaur ere Donibane Lohitzunen arraba deitzen dena.

ARMATU, a rmer, a rmer, 103. Adiera berezia dela eman zitekeen, fr. 'forcir' alegia.

ARRASATU, tailler en ras, a rrasar, 99. Hobe 'raser'.

ARROLACA, trebuchent, en zig-zag, 98. 'En trébuchant' da ; fr. eta gazt. bi hitzek ez dute gauza bera adierazten.

ARRUTA, route, ruta, 157. Adiera teknikoa dela gehi zitekeen.

ACUCRE. AÇUCRE behar da.

BABAÇUÇA, grêle, pedrisco. 'Pedrisco' hori 'granizo grueso' da Molineren arabera eta aldiz Euskal Herriko leku hanitzetan babazuza harria baino xeheago dela iduri luke. Hiztegiek ez dute argi handirik ematen eta Urkizuri ezin zaio xehetasun gehiagorik galdatu. Aukeran 'grésil, granizo' eman genezake, 'grésil' 'grêle' baino xeheago delakoan.

BENTURATZEN, 94, ez du glosatzen. 'Aventurer', 'mettre en jeu', 'risquer' eman zitekeen, gogoan hartuz 'aventure' hitza erabilia izan dela itsas-bidaietako segurantza-mota baten izendatzeko (cf. 'prêt à la grosse aventure').

BISLAIA hitza ez du glosatzen, 122. Egia erran, ez dakigu zer erran nahi duen eta originala kontsultatu behar da. OEH-k ez dakar.

BIZARKI hitza ez du glosatzen. Sarrera behar luke. Lhandek ematen duen bizarro, 'généreux' gogoan harturik, 'libéralement, généreusement' glosa diteke.

BURIJESA, bourgeois, burgués, 106. Zehazkiago 'armateur'.

BUTATU, jeter, arrojar, 137. Bainan hemen ez da adiera egokia pilota jokuaz mintzatzen den ber. Iparraldean eta frantsesez 'buter' erraiten da edo bestenez 'engager', 'mettre la balle en jeu'. Zernahi gisaz, testuak 'butan' dakar eta ez 'butatu'.

BUTARI, jeteur, la nzador, 137. Goiko lerroan erraiten dugunaren arabera, 'buteur' emaitea hobe da.

DESGOGARA, contre le gré, con desagrado, 135. Hobe 'de mauvais gré', 'à contrecœur'.

ECHUATU, échouer, fra ca sar, 107. Bainan 'encallar' erran nahi du testuak : va issea u batec malhuruski costan du echuatu. Ez da edozoin 'fracaso'. Gogoan har hitz hori ez duela begi onez ikusten egileak, frantsesca ra baitzaio.

ERLACHA, mur, muro, 143. Urkizuk hitz hori lotzen du erlax sarrerarekin. Ez da dudarik fr. 'relâche' ('lieu où un navire fait escale' edo 'action de relâcher') duela iturburu eta horrela egin du ere OEH-k, hain zuzen hemengo pasartea aipatuz.

ERREFERA, reponse ('réponse' behar du) à la balle, devolución de la pelota, 137. Iparraldean, frantseses 'refil' hitza baliatzen da pilota jokoaz den bezenbatean ('renvoi' hitza ere onar diteke). 'Réplique' edo 'riposte' erabiltzen ahal da zentzu metaforikoan.

ERREPIRA, cours, curso, 116. 'Cours d'eau', 'rivière' behar da. Egia da ez dela 'rive'.

ESTOFA, éttofe, estofa, 127 ; 'étoffe' behar da. 
FRANTSESCARA, gallicisme, galicismo, 108. Bainan hemen idazleak deitoratzen dituen erdarakadak ez ote dira 'gallicisme' baino piesago ?

FUNTANCHA, fonta nche, lazo de toca do antiguo de señora, 173. Guziz zuzen dabil Urkizu erranahiaren aldetik eta fr. 'fontanges' ezarri behar da. TLF-k horrela dio : «Nœud de rubans porté aux XVIIe et XVIIIe siècles par les femmes un peu au dessus $\mathrm{du}$ front pour retenir leurs cheveux [...] Du nom de la duchesse de Fontanges (1661-1681), maîtresse de Louis XIV (1679-1680), qui lança la mode de cette coiffure en nouant, au moyen d'un ruban, ses cheveux dérangés par le vent lors d'une partie de chasse. Cette coiffure plut au roi et fut imitée par les dames de la cour».

GABIA, gabie, gavia, 97. Oraiko irakurleak hobeki ezagutzen duen hitza 'hune' da eta gehi zitekeen.

GAMBARAÇAIN, gardien de chambre, a yuda de cáma ra, 112. Hobe 'chambrière'.

GANTÇUTU, graisser, engordar, 123. Hobe 'graisser, oindre' eta 'untar', ez 'engordar'. Gantza fr. 'panne' da, erran nahi baita zehazki urdearen parte urinzua (hartarik ateratzen den uringatzgabea fr. 'saindoux' da) nahiz 'panne' hitz hori ez duten aipatzen ez Lhandek, ez OEH-k.

GARNIÇON, garde, guarnición. 'Garnison' behar da.

GARAMBORE, instrument musicale, ga rambaina, 150. 'Instrument musical' behar da. Hitza ez dugu ezagutzen.

GARRAIATU, charrier, acarrear, 107. Bai bainan gaurko irakurlearentzat 'charroyer', 'transporter' ere hobeki ulertzen da.

GOARDACORSA, garde corse, guarda corsa , 158. Ezin da hori izan. Originala ikusi behar. Gaude ez ote den besterik gabe 'garde du corps','guarda-espalda'.

GRECA, 124 ez du glosatzen. Lhandek ematen dituen adierak, 'bégaiement' eta 'bègue' ez dira hemen egoki. Moda, jantzi eta edergailuetako alorreko hitza da eta fr. 'coiffure à la grecque' glosatu behar da. Bidenabar, Lhandek dakarren greka hitzaz xehetasun bat eman gabe ez nagoke ezen ez dut uste hitz horren adiera 'bègue' izan denik bakarrik. Baxenaparrean bildu dudanaren arabera, greka deitzen zen ahoskatzeko akatsa zuen jendea, hots /rr/darkarkari anizkuna ematen ez zuen jendea, eta dardarkariaren ordez frantsesezko [R] 'grasseyé' ematen zuen jendea, non ikusten baitugu belaunaldi gutiren barnean greka bilakatu garela Iparraldeko euskaldun gehienak gaur ez baitezakegu [R] hortaz besterik egin euskaraz. Duela guti (bi belaunaldi beraz edo 60 urte hor nonbait) estigmatizatua zena kasik guziz nagusitu da oldar handiz.

ICUSCARI, vision, visión, 116. Hobe 'spectacle'.

KALENDABUXAK, 125, falta da. Ka lendabuxak hitza zer den ez dugu zilatu, bainan kalenda zer zitekeen bai. Fr. 'calandre' proposatzen dugu, eta 'greka' bezala biloen emateko modu berezi baten izena da. TLF-k ematen dituen adieretan ez da ageri hemengo adiera. TLF-aren arabera 'calandre' xori baten izena (allauda mota bat) da, edo intsektu baten izena, edo otomobiletako burdinezko pieza bat, edo azkenik oihalaren edo paperaren lisatzeko tresna baten izena. Bainan 'la coiffe calandre' web-ean hatzeman dugu eta oraindikan Antillesetan erabiltzen omen da.

CAMAINA, lit de paille, lecho de paja, 102. Hobe 'paillasse' edo 'couchette'.

KHORROKAN, en ronflant, roncando, 137. Kontestua kontuan harturik hanitzez 
hobeki dator OEH-k ematen duen 'râle' adiera, edo 'être aux abois', metaforikoki. Testuak khorrokan hitza paraleloan ematen du hill urren, hagonian, eta kandelan lexiekin. Zentzu horretako khorroka hitza guziz ezaguna da gaur ere Baxenafarroan bederen eta erabiltzen da norbait ttipi delarik, erran nahi baita agonian sartua delarik, eta preseski hil aintzineko 'khorrokak' ematen dituelarik.

KOARTERA, 99. Gazt. 'cuartero : madero de dimensiones varias' badago bainan kontuan hartu behar da ez dela zur puska bakar batez ari testua : Coartera dio eraman [itxasoak] eta zuzenago iduritzen zaigu gazt. 'cuartel' proposatzea ondoko adiera honekin : 'compuesto o armazón de tablas con que se cierran las bocas de las escotillas, escotillones, cañoneras' (DLERAE). Fr. 'panneau d'écoutille' proposatzen dugu. Ikus adibidez Fournier 1667 : 'Escoutilles, sont grands panneaux, par lesquels on ouure les ponts \& Tillacs pour descendre ou tirer de grands fardeaux d'vn vaisseau' edo ber liburuan: 'Escoutillon, est vne ouuerture quarrée, qui est dans les escoutilles, par laquelle on sort, \& deualle dans vn vaisseau'. Berdin Du Guay-Trouin, 1740 : 'Escoutille. Ouverture ou trape par laquelle on descend entre les ponts, \& la cale'.

CUCULDU, s'engourdi, entumecido, 126. Zernahi gisaz 'engourdi' behar liteke zuzenez bainan semantikaren aldetik hobeki heldu da OEH-k dakarren lehen adiera : 'desaparecer, esconderse, couvrir, se couvrir d'un voile, d'un manteau qui empêche d'être vu'. Alabainan testuak horrela dio : Ethorri çayo dolua/ordutik du mandelua,/ munduko legueac nahi baitu/ibil dadin cuculdua.

LUIETAN, 187, falta da. Fr. 'en louvoyant' eman behar da, hemen erranahi metaforikoan erabilia, erran nahi baita 'nahikatua den xedera xuxen joan gabe mila itzuli-mintzuli egitea'.

MANDELU, moudre, mosca, 126 : 'mouche' behar liteke bainan erranahiaren aldetik ez dugu uste zuzen den adiera hori 'mando-euli'-rik ez baita hemen ageri. Originala ikusi behar da bainan manta, mantaleta, mantalina, manteleta hitzen aldakitzat hartzen dugu hemengo mandelu, hots fr. 'mantelet'.

MASCARADA, 98 falta da. Zuberoko ikusgarriarekin ez du deus egitekorik, prefosta (etimologiaz kanpo). Hitz hortaz Franzözische Etymologische Wörterbüchek argi haboro ematen digu. Italierazko maschera oinarritzat harturik (bainan latinez masca hitzak jadanik 'sorgin', 'belagile' edo 'inguma' erran nahi zuen). Etimoi hartatik atera diren formak (izen eta eratorri guziak) gaingiroki sailka ditezke semantikoki. Alde batetik begitartea kukutzen duen 'maska' da. Izaiten ahal da ere, erran bezala, 'sorgin' bat, 'prostituta' bat, 'emazteki bihurri' bat, 'ametsgaizto' bat (ametsgaiztoaren eta ingumaren arteko lotura ezaguna da), 'zorigaizto', 'jende faltsu', 'mamu' etabar. OEH-k maska ematen du adiera hoietarik zonbait aipatuz. Bestalde 'zikindu', 'theiutu' erran nahi duen aditza badago (ikus mazkildu OEH-n, eta iparraldeko frantsesez egun ere erabiltzen den 'mâcher : les eaux sont mâchées, 'zikin', 'thürbüts' direlakoan), gero, lerraketaz, 'ilun' eta 'beltz' erran nahi duen adjetiboa badago ere (ikus euskaraz mazkaro, maska ro ere buruan, muturrean tona iluna duen kabale batez, biarnesez mazkar), gero 'lan gaiztoa' denotatzen ahal du (matxuratu ez ote da hortik jiten ?), eta azkenik 'disimulatu', 'aspertu', 'kukutu' adieraz dezake. Alor teknikoetan ez da ezezaguna eta Von Wartburgen bilduma harrigarriak preseski itsas-munduari buruzko adiera bereziak ematen ditu. Erreferentziak zehatz mehatz nahi dituenak jo beza FEW-ra, 'masque' hitzak bospasei adiera baitauka itsasuntziei buruz ('bela' baten izena da besteak beste). Horra zer dioen 'masquer' aditzaz : 'frapper par devant, arrêter [untzi bat], en 
parlant du vent qui saute'. Beste adiera hau ere badago : 'Masquer : avoir ses voiles prises à contre par suite d'une saute de vent'. Gehiago dena, gure euskarazko dokumentuko testinguruan ongi heldu diren beste adierak badaude, hain zuzen aroari buruz emanak, 'mascarade' hitzaz: 'Saint. [Saintonge erran nahi duke] gros nuage, avant-coureur de la pluie' edo Saintonge-n ere : 'Sorte de tempête avec grêle'. Okzitaneraz 'masco' hitza Béziers-en bildua izan da : 'nuage qui s'élève de la mer, et qui annonce la pluie ou l'orage'. 'Mascore' hitza bildua izan da adiera bertsuan; 'h.lim [haut-limousin] : vent très fort'. Gure testuan dagoen maska rada hitza ez dabil urrun semantikaren aldetik. Dudarik gabe euskal idazleak itsa soak maska rada pasartean horrelako zerbait adierazi nahi du : 'tanpez gertatzen den aroaldaketa handi baten ondotik, sorpresaz bezala, heldu den aize edo eta harri erauntsi bortitza, untziaren ibilera net erasotzen duena', antropomorfismo inkau bat dela medio.

MUNDUTARRA, 184 falta da. Erlisionean duen adiera proposatzen dugu, fr. 'mondain'.

NASCA, suffissa nt, suficiente, 152. 'Suffisant' behar du bainan originala ikusi gabe ere, dudazko forma dela susmatzen dugu.

OÇAR, chien, perro, 120. Hobe 'mâtin'.

PAPAIO, bou, duende, 103. Dudarik gabe 'perroquet' ezarri behar da ; 'voile haute et carrée établie au-dessus des huniers. Il y a un grand perroquet au-dessus du grand hunier et un petit perroquet au dessus du petit hunier (TLF)'. Ikus ere Consolin 1859 : 'Voile carrée qui établit au-dessus des huniers. Celui du grand mât s'appelle grand perroquet; celui du mât de misaine, petit perroquet; celui d'artimon s'appelle perruche'. Ez du deus egitekorik pertsonai mitiko edo izugarri batekin. Jakina da frantsesez 'perroquet' hitzak baztertu dituela papaio-ari hurbil diren forma zaharrak, 'papegai' eta 'papegaut'.

PHEÇA ez da glosatzen, 137. 'Pièce (d'artillerie), canon'.

PONTU, rime, rima , 115. Testuak ez du hori adierazten, hobe 'vers' emaitea.

PURRIÑA, odeur fétide, hedor, 105. Ez da hori. Testuingurua fr 'coaltar' edo horrelako zerbait proposa genezake, hots istupak bezala untziko taulen arteko guneak betetzen dituen ekai baten izena. Deus ez du ikustekorik urrin hitzarekin, are gutiago fr. 'purin' lexiarekin.

REALQUI, royalment, realmente, 161 . 'Royalement'.

SEGO, 123 falta da. 'Suif' da izatez, beste nunbait bilgor deitzen dena (BN-n adibidez).

SEREINA, serein, sereno. Izena dela zehaztea ('aratseko ihintza') ongi liteke. Gaur ere komunzki erabiltzen den hitza da, ze(r)ena forman.

SOCHORRI, secourir, socorrer, 121. 'Secours' : izena da.

SINTSA, 174, falta da. Lhandek dioena : 'dévote acariâtre, béguine' ongi doakio.

TREBES, travers, través, 99. Erran nahi teknikoa duela gehi diteke, itsasuntziari gertatzen zaion ezbeharretarik bat alegia.

TTIMPLA, bandelette, ornement volant de la coiffure des femmes, tombla dera , 101. Askoz egokiago da Lhandek ematen duen bigarren adiera ; 'girouette' testua ongi ulertzen 
badugu : burua du arin, ttimpla baten berdin/ ezquilla dorrecotçat, hä̈ce seiñaleçat. Badakigu tresna horrek preseski buru arina edo nortasunik eza konotatzen duela.

CHAMPELA, crinière, melena, 128. Hobe 'crin'. Baina zurda hitza ere testuak ematen baitu ondo-ondoan, hobe liteke 'crin' ematea zurda-ren ordain gisa, eta 'pite' champela-ren ordaintzat.

CHANTALAK, chanteuse, cantora, 173. Ez dugu uste zuzena den hori eta beste hipotesi bat proposatzen dugu. Ez ote dira 'Visitation' deitu kongregazioko serorak xantal gisa ezagutuak izan euskaraz, kongregazio horren sortzaileak François de Sales et Jeanne de Chantal sainduak direlarik, azken emazte honek bere izena eman zielarik kongregazioko serorei ? Badu kolorerik hala den.

CHORROINTTO, petit quenouillée de lin, rueca pequeña, 123. 'Petite' behar da. Bestalde fr. eta gazt. ez dira bat etortzen eta uste izateko xorrointto izari bat dela eta ez tresna bat.

ÇAKHUTTO, petit bourse, bolsito, 182. 'Petite bourse'.

CEPO, prison, carcel. Hobe 'cep', 'chaîne', 'les fers aux pieds'.

Ondotik ematen ditugu aditz-formetan zuzenketa hartze dituzten hitzak.

BALEGO, s'il restât, si él estuviera. 'S'il restait' eman behar.

BETÇO, qu'il lui les a it, se los ha ya él. 'Qu'il les lui ait' ezar.

DARITZ, ils manent, manan. 'Ils coulent' ezar.

DEIÑO, tant qu'il soit, mientras es. 'Tant qu'il est' ezar.

DEMOGUN, donons-à lui, concedámosle. 'Donnons-le lui'.

$D E C ̧ A D A N T C ̧ A T$, à a fin de que j'ai, pa ra que yo ha ya. 'Afin que j'aie'.

$D E C ̧ A T E N$, qu'ils la ient, que lo ha yan. 'Qu'ils l'aient'.

ZUQUEEN, il pourra it l'a voir, lo podría haber. Hobe 'il pouvait l'avoir'.

Gure zuzenketek ez dute estali nahi P. Urkizuk argitaratu duen obraren interesa, urrundik ere. Gune ilunak badauzka oraino bertso horietan ageri zaigun lexikoak eta beste ikerketa zonbaiten beharrean gelditzen da.

Adibidez ezpartza hitza, 105 orrialdean, behar luke hiztegi teknikoen argia, lemaren eta lemakanaren parteak nola deitzen ziren jakiteko bederen. Frantsesez ezagunak balinbadira 'gouvernail' lexiaren meronimoak, hala nola 'aiguillot', 'barre', 'étambot', 'jemelot', 'mèche', 'piton de cervelle', 'sauvegarde', 'savate', 'semelle', 'talon', 'trou de jaumière' aldiz euskaraz gauzak ez dira hain zehatz eta espartza brankako parte hoietarik bat izan behar litekeela edo eta lema bat hausten zeneko haren ordez ezartzen zen behinbehineko tramankuluaren parte bat izan litekeela uste badugu ere ez dugu hori zilatu, alderdi entziklopedikoari doakion alorra gutiegiz arakatuz. Halere, araiz, irakurlea lagunduko dute hona ekarri ditugun oharrek. 